\title{
ФЕНОТИПИЧЕСКАЯ УСТОЙЧИВОСТЬ К АНТИБИОТИКАМ У ШТАММОВ Staphylococcus aureus, ВЫДЕЛЕННЫХ ИЗ МОЛОКА КОРОВ
}

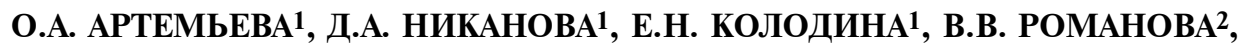 \\ Ф.А. БРОВКО1, Н.А. ЗИНОВБЕВА ${ }^{1}$
}

\begin{abstract}
Из-за постоянного использования антимикробных препаратов в последние десятилетия резко обострилась проблема появления мультирезистентных штаммов. Инфекции, вызванные Staphylococcus aureus, наиболее распространены у высокопродуктивных животных молочного направления. Целью нашей работы было оценить фенотипическую устойчивость штаммов Staphylococcus aureus, выделенных из молока коров, к основным антибактериальным препаратам, используемым для лечения различных форм мастита на территории Российской Федерации, а также определить их минимальные ингибирующие концентрации (МIC, $\mathrm{MIC}_{50}$ и МIC 90 ). Пробы молока отбирали в хозяйствах Центрального региона России в период с января по декабрь 2018 года от коров черно-пестрой голштинизированной породы. Всего было исследовано 314 образцов молока и выделено 447 потенциальных изолятов стафилококков. Все изоляты оценивали общепринятыми фенотипическими методами. Только 103 удовлетворяли всем критериям идентификации и использовались для последующего анализа. Тестирование чувствительности выделенных штаммов проводили диско-диффузным методом (ДДМ) к следующим антибиотикам: пенициллину (Pen, 10 ЕД), оксациллину (OX, 10 мкг), гентамицину (GN, 10 мкг), эритромицину (ER, 15 мкг), линкомицину (LN, 15 мкг), рифампицину (RF, 5 мкг), ципрофлоксацину (CP, 5 мкг), ванкомицину (VA, 30 мкг), фузидину (FZ, 10 мкг) (ЗАО «Научно-исследовательский центр фармакотерапии», Россия) на среде Mueller Hinton Agar («HiMedia Laboratories Pvt. Ltd.», Индия). Минимальные ингибирующие концентрации (MIC, $\left.\mathrm{MIC}_{50}, \mathrm{MIC}_{90}\right)$ и $\mathrm{LD}_{50}$ определяли методом 2кратных $\left(\log _{2}\right)$ серийных разведений (от 64 до 0,125 мг/л) антибиотиков (пенициллин, эритромицин, гентамицин, ципрофлоксацин) в среде TSB с инокулюмом $5 \times 10^{5} \mathrm{KOE} /$ мл. Инкубирование осуществляли при $37^{\circ} \mathrm{C}$ в течение 20 ч на качалке (220 об/мин). Рост культур в среде TSB с антибиотиками оценивали при пересеве на среду Baird Parker Agar («HiMedia Laboratories Pvt. Ltd.», Индия). Результаты интерпретировали по рекомендации The European Committee on Antimicrobial Susceptibility Testing (EUCAST). Наивысшая степень устойчивости наблюдалась к эритромицину $(82,5 \%)$ и фузидину $(75,7 \%)$. Из 103 штаммов 7 были чувствительны ко всем исследуемым антибиотикам, 96 изолятов оказались устойчивы по крайней мере к одному из них. При оценке множественной устойчивости (MAR) 65 (63,1 \%) штаммов оказались резистентны к четырем и более антибиотикам. Преобладающими фенотипами для выделенных изолятов были $\mathrm{ER}+\mathrm{LN}+\mathrm{FZ}$ и $\mathrm{ER}+\mathrm{CP}(58,3 \%$ и 47,6 \% изолятов). Из 47 изолятов, устойчивых к пенициллину по ДДМ, 31 штамм продемонстрировал рост при концентрациях пенициллина $\geq 64$ мг/л, при этом в диапазоне $\leq 1,0$ мг/л рост наблюдался у 33,0 \% штаммов. Из 85 изолятов, устойчивых к эритромицину, 15 проявляли рост при МIC $\geq 64$ мг/л, в диапазон МІС $\leq 0,5$ мг/л попали только 7 штаммов из 18 чувствительных по ДДМ. Из 103 исследуемых штаммов 29 (28,2 \%) были устойчивы к гентамицину по ДДМ и $72(60,2 \%)$ проявляли рост при МІС $\geq 0,5$ мг/л, а 5 штаммов - при МIC $\geq 64,0$ мг/л. Из 49 устойчивых по результатам ДДМ штаммов только у двух наблюдался рост при $\mathrm{MIC} \geq 64$ мг/л. Важно отметить, что величина $\mathrm{MIC}_{50}$ не находилась в восприимчивом диапазоне ни для одного из исследуемых антибиотиков, а МІС 90 показала восприимчивый диапазон для пенициллинов, аминогликозидов и фторхинолонов - соответственно > 0,5; $>0,25$ и > 0,25 мг/л. Высокая фенотипической устойчивости изолятов S. aureus из молока коров в нашем исследовании подчеркивают важность рутинного скрининга изолятов S. aureus на индуцибельную фенотипическую резистентность.
\end{abstract}

Ключевые слова: мастит, Staphylococcus aureus, антибиотики, антибиотикочувствительность, МIC, фенотипическая резистентность.

Формирование и распространение устойчивых бактерий - естественный и неизбежный процесс, однако его скорость напрямую зависит от селективного прессинга антибиотиков, выраженность которого, в свою очередь, определяется объемом применения этих препаратов как в медицине, так и в сельском хозяйстве (животноводстве и ветеринарии) (1). Инфекции, вызванные Staphylococcus aureus, наиболее распространены у высокопродуктивных животных молочного направления. В связи с постоян-

\footnotetext{
* Исследования выполнены при поддержке РНФ, проект № 15-16-00020-П.
} 
ным использованием антимикробных препаратов за последние десятилетия резко обострилась проблема появления мультирезистентных штаммов, что делает актуальным вопрос антибиотикотерапии маститов.

Группы макролидов, аминогликозидов и пенициллинов, включающие антибиотики бензилпенициллин, эриромицин, амоксициллин и гентамицин, часто используются в лечении мастита коров на территории Российской Федерации (2-4). Результаты исследований на чувствительность in vitro - важный инструмент при выборе наиболее эффективного антимикробного агента для терапевтического и профилактического вмешательства. Субингибирующие концентрации (суб-МIC) антибиотиков вызывают обширные транскрипционные изменения в бактериальной клетке, влияют на адгезионную способность и развитие устойчивости к антибиотикам $(5,6)$. В этом случае антибиотики действуют как сигнальные молекулы и способны модулировать бактериальные фенотипы. Известно, что суб-МІС антибиотиков, основной механизм действия которых заключается в повреждении ДНК, усиливают мутации у бактерий. У $S$. aureus в присутствии макролидов (эритромицин, кларитромицин и азитромицин) и $\beta$-лактамных антибиотиков (пенициллин, оксациллин, цефалексин, цефалотин и ванкомицин) индуцируется экспрессия генов, определяющих образование биопленок (БП) (7-9). Цефалоспорины инициируют синтез белков, но не влияют на экспрессию генов системы Quorum Sensing (QS), модулирующей формирование БП $(10,11)$. Установленные биопленки устойчивы к распространенным противомикробным препаратам, что требует более эффективного подхода и развития стратегий по контролю БП в медицине и ветеринарии.

Наличие репрезентативной выборки при проведении микробиологического анализа молока имеет первостепенное значение для постановки правильного диагноза (12). Механизмы развития антибиотикоустойчивости различны - от спонтанного продуцирования фермента и антимикробной избирательности клеточной стенки до efflux-систем $(13,14)$. Признаки устойчивости к антимикробным агентам кодируются генами, которые могут переноситься на бактериальной хромосоме, плазмидах, транспозонах или на генных кассетах, включенных в интегроны (15-17). У штаммов $S$. aureus показано присутствие генов устойчивости $\operatorname{rpoB}, \operatorname{blaZ}$, mecA (18), aacA-D, tetK, tet $M, \operatorname{erm} A(19,20), \operatorname{msr} A(21), \operatorname{lin} A, \operatorname{vat} A, \operatorname{vat} B, \operatorname{dfr} A, \operatorname{gyr} A, \operatorname{grl} A$, cat1 к антибиотикам групп ансамицины, пенициллины, аминогликозидам, тетрациклинам, макролид-линкозамид-стрептограминам В, линкозамидам, стрептограминамам и фторхинолонамам $(22,23)$. Устойчивые к пенициллину изоляты несут плазмидный ген $b l a Z$, который кодирует $\beta$-лактамазный фермент, называемый пенициллиназой $(24,25)$.

У $S$. aureus появление и распространение устойчивости к пенициллиназе называют первой волной устойчивости, развитие устойчивости к метициллину - второй. Последняя опосредована наличием гена $m e c A$, кодирующего низкоафинный белок, который связывает пенициллин (PBP2a) (26). Устойчивость к хинолонам у $S$. aureus возникает поэтапно благодаря точечным мутациям (главным образом, в генах субъединицы GrlA топоизомеразы IV и субъединицы GyrA гиразы), а также экспрессии гена norA, кодирующего белок NorA с функцией основного откачивающего насоса (NorA efflux pump). Изоляты $S$. aureus, устойчивые к аминогликозидам, продуцируют три типа аминогликозид-модифицирующих ферментов (AMЕ) (27) aminoglycoside-3"-O-phosphoryltransferase III [aph(3')-III] (28), aminoglycoside4'-O-phosphoryltransferase I [ant(4')-I] (29) и aminoglycoside-6'-N-acetyltransferase/2"O-phosphoryltransferase [aаc(6')/aph(2")] (30), которые модифицируют соответственно аминогликозиды канамицин, тобрамицин и гентами- 
цин $(31,32)$. Изучение устойчивости $S$. aureus к макролидам показывает, что erm, кодирующие рибосомальные метилазы, - наиболее часто встречающиеся гены, определяющие устойчивость к эритромицину $(33,34)$.

В настоящей работе впервые описана суточная динамика активности штаммов $S$. aureus из молока высокопродуктивных коров в среде с высокими концентрациями антибактериальных препаратов. Выявлена прямая корреляция между устойчивостью штаммов при оценке методом дискодиффузии (ДДМ) и по минимальным ингибирующим концентрациям. Впервые представлены данные о комбинированной резистентности к антибиотикам у штаммов $S$. aureus, обнаруженных в молоке коров в Центральном регионе России.

Нашей целью было оценить фенотипическую устойчивость штаммов Staphylococcus aureus из молока коров к основным антибактериальным препаратам, используемым для лечения мастита в Российской Федерации, и определить их минимальные ингибирующие концентрации (MIC, $\mathrm{MIC}_{50}$ и $\left.\mathrm{MIC}_{90}\right)$.

Методика. Пробы молока отбирали в хозяйствах Центрального региона России в период с января по декабрь 2018 года от коров (Bos taurus taurus) черно-пестрой голштинизированной породы. Отбор осуществляли асептически в период доения (от каждого животного через 60-70 сут после отела). Образцы доставляли в лабораторию при температуре $+4{ }^{\circ} \mathrm{C}$ в течение 2 ч либо в замороженном состоянии при $-20^{\circ} \mathrm{C}$.

Все изоляты оценивали общепринятыми фенотипическими методами: микроскопия колоний с окрашиванием по Граму; рост на среде Baird Parker Agar («HiMedia Laboratories Pvt. Ltd.», Индия); гемолиз на среде Azide Blood Agar Pronadisa («Conda», Испания); положительный результат плазмокоагуляции (ЗАО «ЭКОлаб», Россия); биохимическая идентификация с использованием микробиологических сред и панели API 20 STAPH («BioMerieux», Франция). Штаммы для дальнейших исследований хранились в пробирках с Trypticase Soy Broth (TSB, «Merck», Германия) с добавлением 30 \% стерильного глицерина («Sigma», CША) при $-18{ }^{\circ} \mathrm{C}$.

Чувствительность штаммов к пенициллину (PEN, 10 ЕД), оксациллину (OX, 10 мкг), гентамицину (GN, 10 мкг), эритромицину (ER, 15 мкг), линкомицину (LN, 15 мкг), рифампицину (RF, 5 мкг), ципрофлоксацину (CP, 5 мкг), ванкомицину (VA, 30 мкг), фузидину (FZ, 10 мкг) (ЗАО «Научно-исследовательский центр фармакотерапии», Россия) тестировали диско-диффузным методом (ДДМ) на среде Mueller Hinton agar («HiMedia Laboratories Pvt. Ltd.», Индия). Скрининг метициллин-резистентных изолятов $S$. aureus (MRSA) осуществляли с использованием дисков с цефокситином (CF, 30 мкг) (35).

Минимальные ингибирующие концентрации (МIC, $\mathrm{MIC}_{50}, \mathrm{MIC}_{90}$ ) и $\mathrm{LD}_{50}$ антибиотиков определяли методом серийных разведений в среде TSB. Для этого из агаровой культуры готовили инокулюм исследуемых штаммов $S$. aureus с плотностью 0,5 по стандарту мутности МакФарланда (McFarland Standard). Антибиотики растворяли в физиологическом растворе. Исследовали двукратные $\left(\log _{2}\right)$ серийные разведения антибиотиков (пенициллин, эритромицин, гентамицин, ципрофлоксацин) в концентрациях от 64 до 0,125 мг/л, которые готовили согласно методическим указаниям (36). Тестирование проводили в объеме 1 мл каждого разведения антибактериального препарата (АБП) с исследуемым микроорганизмом в количестве примерно $5 \times 10^{5} \mathrm{KOE} /$ мл. Инкубирование осуществляли при $37{ }^{\circ} \mathrm{C}$ в течение 20 ч на качалке при 220 об/мин. Рост культур в среде TSB с антибиотиками оценивали методом пересева на среду Baird Parker Agar. 
Результаты интерпретировали по рекомендации The European Committee on Antimicrobial Susceptibility Testing (EUCAST) (37).

Биометрическую обработку проводили с использованием программ Microsoft Excel 2010, SAS версия 6.12 («SAS Institute», США).

Результаты. Всего было исследовано 314 образцов молока от высокопродуктивных коров и выделено 447 потенциальных изолятов стафилококков, из которых только 103 удовлетворяли всем критериям идентификации и использовались для последующего анализа. Эта степень загрязнения аналогична той, которую отмечали в исследованиях, проведенных ранее в России $(37,38)$ и других странах $(39-41)$.

Наивысшая степень устойчивости изолятов $S$. aureus в условиях in vitro наблюдалась к эритромицину $(82,5 \%)$ и фузидину $(75,7 \%)$ (табл. 1$)$. Только у 7 выделенных штаммов $(6,8 \%)$ выявили чувствительность ко всем исследуемым антибиотикам, тогда как 96 изолятов оказались устойчивы по крайней мере к одному из них. Другими авторами было установлено очевидное развитие резистентности $S$. aureus к пенициллину, ампициллину, эритромицину $(40,42,43)$.

1. Антибиотикочувствительность штаммов Staphylococcus aureus, выделенных из молока коров черно-пестрой голштинизированной породы в хозяйствах Центрального региона Российской Федерации (2018 год)

\begin{tabular}{|c|c|c|c|c|c|c|c|c|c|}
\hline \multirow{3}{*}{ Антибиотик } & \multirow{3}{*}{$\begin{array}{l}\text { Концентрация } \\
\text { препарата }\end{array}$} & \multicolumn{4}{|c|}{$\operatorname{MSSA}(n=47)$} & \multicolumn{4}{|c|}{ Общее число штаммов $(n=103)$} \\
\hline & & \multicolumn{2}{|c|}{ резистентные } & \multicolumn{2}{|c|}{ чувствительные } & \multicolumn{2}{|c|}{ резистентные } & \multicolumn{2}{|c|}{ чувствительные } \\
\hline & & $n$ & $\%$ & $n$ & $\%$ & $n$ & $\%$ & $n$ & $\%$ \\
\hline Pen & 10 ЕД & 47 & 100 & 0 & 0 & 47 & 45,6 & 56 & 54,4 \\
\hline OX & 10 мкГ & 0 & 0 & 47 & 100 & 0 & 0 & 103 & 100 \\
\hline GN & 10 мКг & 20 & 42,6 & 27 & 57,4 & 29 & 28,2 & 74 & 71,8 \\
\hline ER & 15 мКг & 41 & 87,2 & 6 & 12,8 & 85 & 82,5 & 18 & 17,5 \\
\hline $\mathrm{LN}$ & 15 мКг & 31 & 66,0 & 16 & 34,0 & 61 & 59,2 & 42 & 40,8 \\
\hline RF & $5 \mathrm{MK \Gamma}$ & 30 & 63,8 & 17 & 36,2 & 49 & 47,6 & 54 & 52,4 \\
\hline $\mathrm{CP}$ & 5 мКг & 37 & 78,7 & 10 & 21,3 & 49 & 47,6 & 54 & 52,4 \\
\hline VA & 30 мКг & 0 & 0 & 47 & 100 & 0 & 0 & 103 & 100 \\
\hline FZ & 10 МКг & 42 & 89,4 & 5 & 10,6 & 78 & 75,7 & 25 & 24,3 \\
\hline $\mathrm{CF}$ & 30 мКг & 0 & 0 & 47 & 100 & 0 & 0 & 103 & 100 \\
\hline
\end{tabular}

П р и м е ч а н и е. Pen - пенициллин, OX - оксациллин, GN - гентамицин, ER - эритромицин, LN линкомицин, RF - рифампицин, CP - ципрофлоксацин, VA - ванкомицин, FZ - фузидин, CF - цефокситин; MSSA - метициллин-чувствительные $S$. aureus.

Во всем мире частота устойчивости стафилококков, связанная с продукцией $\beta$-лактамазы, составляет от 55,7 до 92,6 \% (44). В наших исследованиях у 47 из 103 изолятов были обнаружены фенотипические признаки устойчивости к $\beta$-лактамным антибиотикам. Все 47 (45,6 \%) штаммов оказались устойчивы к пенициллину (100\%), что согласуется с результатами D. Shi с соавт. (45), которые исследовали 206 штаммов $S$. aureus в Монголии, но противоречит данным F.M. Aarestrup с соавт. (46), которые отмечают низкую частоту (10\%) устойчивости к бензилпенициллину в Дании, Норвегии и Швеции. В другой части Европы доля резистентных к пенициллину изолятов варьировала от 23 до $69 \%$ (47).

Устойчивости к оксациллину и цефокситину у всех исследованных нами штаммов мы не обнаружили, что позволяет отнести их к метициллин-чувствительным $S$. aureus MSSA. В случае MSSA считается, что пенициллин превосходит по действию оксациллин, но только если штаммы не продуцируют пенициллиназу (48). Среди 47 штаммов 12 (25,5\%) одновременно обладали резистентностью к 7 антибиотикам (гентамицину, эритромицину, линкомицину, рифампицину, фипрофлоксацину и фузидину).

Показано, что 100 \% изолятов, выделенных из молока коров в Центральном регионе РФ, были восприимчивы к ванкомицину. Этот препарат больше не используется в ветеринарной медицине во многих стра- 
нах, включая Россию, что может объяснять представленные результаты.

2. Комбинированная резистентность к различным антибиотикам у штаммов Staphylococcus aureus, выделенных из молока коров черно-пестрой голштинизированной породы в хозяйствах Центрального региона Российской Федерации $(n=103,2018$ год)

\begin{tabular}{l|c|c}
\hline \multicolumn{1}{c}{ Антибиотик } & \multicolumn{2}{c}{ Чувствительных в выборке } \\
\cline { 2 - 3 } & $n$ & $\%$ \\
\hline Pen + GN & 20 & 19,4 \\
Pen + ER & 41 & 39,8 \\
Pen + LN & 31 & 30,1 \\
Pen + CP & 37 & 35,9 \\
Pen + FZ & 42 & 40,8 \\
ER + CP & 49 & 47,6 \\
Pen + GN + ER & 20 & 19,4 \\
Pen + GN + ER + LN & 16 & 15,5 \\
Pen + GN + ER + LN + RF + CP + FZ & 12 & 11,7 \\
ER + LN + FZ & 60 & 58,3
\end{tabular}

П р и м е ч а н и е. Pen - пенициллин, 10 ЕД; OX - оксациллин, 10 мкг; GN - гентамицин, 10 мкг; ER - эритромицин, 15 мкг; LN - линкомицин, 15 мкг; RF - рифампицин, 5 мкг; CP - ципрофлоксацин, 5 мкг; VA - ванкомицин, 30 мкг; FZ - фузидин, 10 мкг; CF - цефокситин, 10 мкг.

Для 103 штаммов $S$. aureus были определены фенотипы множественной устойчивости (MAR) к антибиотикам (табл. 2). В результате 65 (63,1\%) штаммов оказались резистентны к четырем и более антибиотикам. Максимальная частота комбинированной резистентности наблюдалась для эритромицина + линкомицина + фузидина $(58,3 \%)$ и эритромицина + ципрофлоксацина (47,6 \%). Штаммы, устойчивые к пенициллину, имели более высокую фенотипическую резистентность, чем устойчивые к другим антибиотикам. У 60 штаммов из 103 развилась множественная резистентность.

3. Минимальные ингибирующие концентрации (МIC, мг/мл) для коагулазоположительных Staphylococcus aureus, выделенных из молока коров чернопестрой голштинизированной породы в хозяйствах Центрального региона Российской Федерации $(n=103,2018$ год)

\begin{tabular}{|c|c|c|c|c|c|c|c|c|c|c|c|c|c|c|}
\hline \multirow{2}{*}{$\begin{array}{l}\text { Анти- } \\
\text { биотик }\end{array}$} & \multicolumn{2}{|c|}{ MIC } & \multicolumn{10}{|c|}{ Число ингибированных изолятов для разных МIC } & \multirow{2}{*}{$\mathrm{MIC}_{50}$} & \multirow{2}{*}{$\mathrm{MIC}_{90}$} \\
\hline & Ц3 & Д3 & $\geq 64$ & 32 & 16 & 8 & 4 & 2 & 1 & 0,5 & 0,25 & $\leq 0,125$ & & \\
\hline$\overline{\mathrm{ER}}$ & 0,5 & $0,25-1,0$ & 15 & 10 & 27 & 14 & 10 & 9 & 11 & 3 & 4 & 0 & $>16,0$ & $>1,0$ \\
\hline Pen & $0,25-0,5$ & $0,125-1,0$ & 31 & 10 & 7 & 6 & 8 & 7 & 14 & 12 & 8 & 0 & $>8,0$ & $>0,5$ \\
\hline GN & 0,25 & $0,125-0,5$ & 5 & 13 & 14 & 13 & 11 & 6 & 10 & 13 & 10 & 8 & $>4,0$ & $>0,25$ \\
\hline $\mathrm{CP}$ & $0,5-1,0$ & $0,25-2,0$ & 2 & 8 & 12 & 12 & 13 & 10 & 12 & 14 & 11 & 9 & $>2,0$ & $>0,25$ \\
\hline $\begin{array}{l}\text { П р и м } \\
\text { ницил } \\
\text { погиба } \\
\text { Antimi }\end{array}$ & $\begin{array}{l}\text { о соотв } \\
\text { obial Su } \\
\text { лениям }\end{array}$ & Ц3 - цел & be 31 & чени & ДЗ & O & Іусті & ые & & гения & ER - & эритр & & \\
\hline
\end{tabular}

Значения МІС для выделенных коагулазо-положительных штаммов S. aureus приведены в таблице 3. Поскольку разница в специфичности и чувствительности штаммов $S$. aureus к цефокситину при оценке методами MIC и ДДМ незначительна (2-3 \%), что служит надежным предиктором резистентности к метициллину, исследования МIC для этого антибиотика не проводились (50). Из 47 изолятов, устойчивых к пенициллину по ДДМ, 31 штамм продемонстрировал рост при концентрациях пенициллина $\geq 64$ мг/л, при этом в диапазоне $\leq 1,0$ мг/л рост наблюдали у $33 \%$ штаммов. Значения $\mathrm{MIC}_{50}$ и $\mathrm{MIC}_{90}$ для пенициллина составили > 8,0 и > 0,5 мг/л, что намного выше установленного стандарта для чувствительных штаммов. Высокая резистентность к пенициллину среди $S$. aureus может быть обусловлена использованием интрамаммарных препаратов, содержащих комбинации различных антибиотиков и противомикробных препаратов широкого спектра действия (51).

Из 85 изолятов, устойчивых к эритромицину, 15 проявляли рост 
при $\mathrm{MIC} \geq 64$ мг/л, в диапазон МIC $\leq 0,5$ мг/л попали только 7 штаммов из 18 чувствительных по ДДМ. Показатели $\mathrm{MIC}_{50}$ и $\mathrm{MIC}_{90}$ для эритромицина были максимальны по сравнению со всеми исследуемыми антибиотиками (см. табл. 3). Из 103 исследуемых штаммов S. aureus 29 (28,2 \%) обладали устойчивостью к гентамицину по ДДМ и $72(60,2 \%)$ проявляли рост при $\mathrm{MIC} \geq 0,5$ мг/л, а 5 штаммов - при $\mathrm{MIC} \geq 4,0$ мг/л. Ципрофлоксацин показал наибольшую эффективность в отношении выделенных штаммов $S$. aureus. Так, из 49 устойчивых по результатам ДДМ штаммов только 2 проявляли рост при $\mathrm{MIC} \geq 64$ мг/л; $\mathrm{MIC}_{50}$ и $\mathrm{MIC}_{90}$ для этого антибиотика составили соответственно $>2,0$ и $>0,25$ мг/л. В заключение важно отметить, что MIC $_{50}$ не находился в восприимчивом диапазоне ни для одного из исследуемых антибиотиков, а $\mathrm{MIC}_{90}$ показал восприимчивый диапазон для пенициллинов, аминогликозидов и фторхинолонов.
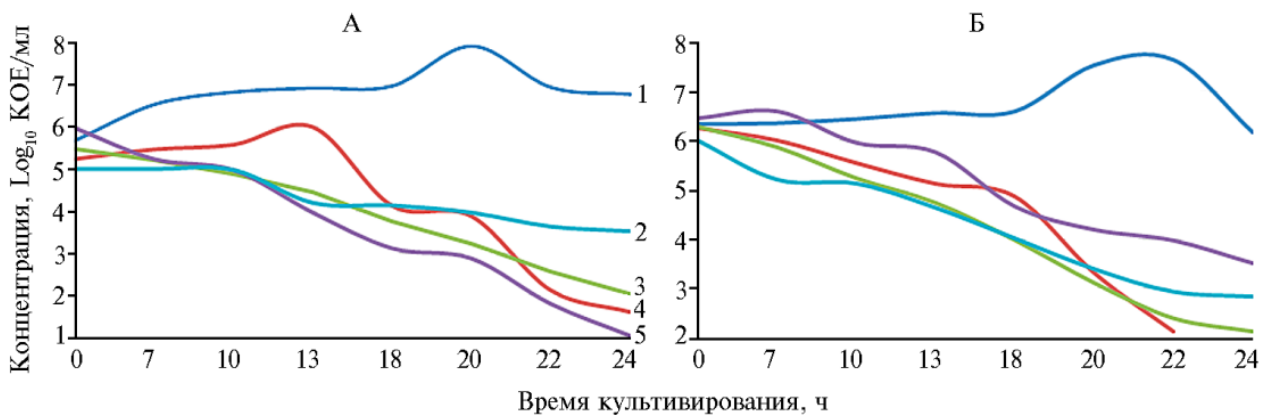

Рост штаммов Staphylococcus aureus 615 (А) и 1839 (Б), выделенных из молока коров чернопестрой голштинизированной породы в хозяйствах Центрального региона Российской Федерации, в зависимости от времени культивирования и вида действующего антибиотика: 1 - контроль, 2 - ципрофлоксацин, 64 мг/л, 3 - гентамицин, 64 мг/л, 4 - пенициллин, 64 мг/л, 5 эритромицин, 64 мг/л.

Из 103 штаммов S. aureus в качестве моделей для изучения действия антибиотиков как подавляющего фактора роста были отобраны 12 мультирезистентных штаммов, устойчивость которых описана выше. Активный рост в среднем для всех штаммов начинался на 7-й ч культивирования (рис.). Присутствие антибиотиков в среде приводило к подавлению или задержке роста. Наблюдаемый эффект зависел от времени культивирования и вида действующего антибиотика. Концентрация пенициллина 64 мг/л приводила к снижению числа жизнеспособных клеток в 83,3 \% случаев, но только у двух культур наблюдалось полное подавление роста на 20-й ч культивирования. Гентамицин, ципрофлоксацин и эритромицив в концентрации 64 мг/л не оказывали полного подавляющего эффекта ни на один из 12 штаммов. К 24 ч культивирования численность клеток $S$. aureus в среде с гентамицином было не ниже $2,84 \log _{10}$ KOЕ/мл, а с эритромицином - не ниже $2,97 \log _{10} \mathrm{KOE} /$ мл. Выживаемость $S$. aureus в среде с ципрофлоксацином составила для разных штаммов от 18,5 до 84,0 \% что свидетельствует о наличии клеток с генами устойчивости к этой группе антибиотиков. Аналогичная зависимость в действии антибиотиков наблюдалась для всех 12 исследуемых штаммов.

Высокая фенотипическая устойчивость изолятов S. aureus из молока коров в нашем исследовании подчеркивает важность рутинного скрининга изолятов $S$. aureus для выявления индуцибельной резистентности фенотипов. Наблюдения за изменениями численности жизнеспособных клеток в течение 24 ч под воздействием высоких концентраций антибиотиков дают возможность проследить развитие резистентности.

Таким образом, из всех изолятов, выделенных из молока коров черно-пестрой голштинизированной породы в хозяйствах Центрального 
региона Российской Федерации, 23,0 \% были отнесены к Staphylococcus aureus, из них 63,1 \% штаммов оказались резистентны к четырем и более антибиотикам. Значения $\mathrm{MIC}_{50}$ и $\mathrm{MIC}_{90}$ для пенициллина составили $>8,0$ и $>0,5$ мг/л, что намного выше установленного стандарта для чувствительных штаммов. Из штаммов Staphylococcus aureus, устойчивых к пенициллину, эритромицину, гентамицину и ципрофлоксацину по оценке диско-диффузным методом, при МІС $\geq 64,0$ мг/л способность к росту подтвердили соответственно 65,$96 ; 17,65 ; 17,24$ и 4,08 \%. На устойчивые штаммы содержание максимальных доз антибиотиков (64 мг/л) не оказало полного подавляющего действия: для всех 12 исследуемых изолятов численность клеток была не ниже $2,84 \log _{10} \mathrm{KOE} /$ мл в среде с гентамицином и $2,97 \log _{10} \mathrm{KOE/мл} \mathrm{-} \mathrm{в} \mathrm{среде} \mathrm{с} \mathrm{эритромицином.} \mathrm{Количество} \mathrm{жизнеспо-}$ собных клеток в среде с пенициллином составило 16,7 \%, с ципрофлоксацином - 84,0 \%. Практическое применение фенотипических методов исследования позволяет выявить антибиотикорезистентность у этиологического агента, вызывающего мастит у высокопродуктивных коров. По результатам работы отобраны штаммы для продолжения исследований по поиску генов резистентности.

\author{
ІФГБНУ ФНЦ животноводства - \\ ВИЖ им. академика Л.К. Эрнста, \\ 142132 Россия, Московская обл., г.о. Подольск, пос. Дубровицы, 60, \\ e-mail: vijmikrob@mail.ru $₫$, DAP2189@gmail.com,n_zinovieva@mail.ru, \\ brovko@bibch.ru; \\ 2ФГБНУ Якутский НИИ сельского хозяйства \\ им. М.Г. Сафронова Сибирского отделения РАН, \\ 677001 Россия, Республика Саха (Якутия), г. Якутск, \\ ул. Бестужева-Марлинского, 23/1, \\ e-mail: varvara.romanova.59@mail.ru
}

Sel'skokhozyaistvennaya biologiya [Agricultural Biology], 2019, V. 54, № 6, pp. 1257-1266

Поступила в редакцию

27 сентября 2019 года

\title{
PHENOTYPIC RESISTANCE TO ANTIBIOTICS OF Staphylococcus aureus STRAINS ISOLATED FROM COW MILK
}

\author{
O.A. Artemeva ${ }^{1}$, D.A. Nikanova ${ }^{1}$, E.N. Kolodina ${ }^{1}$, V.V. Romanova ${ }^{2}$, F.A. Brovko', \\ N.A. Zinovieva ${ }^{1}$
}

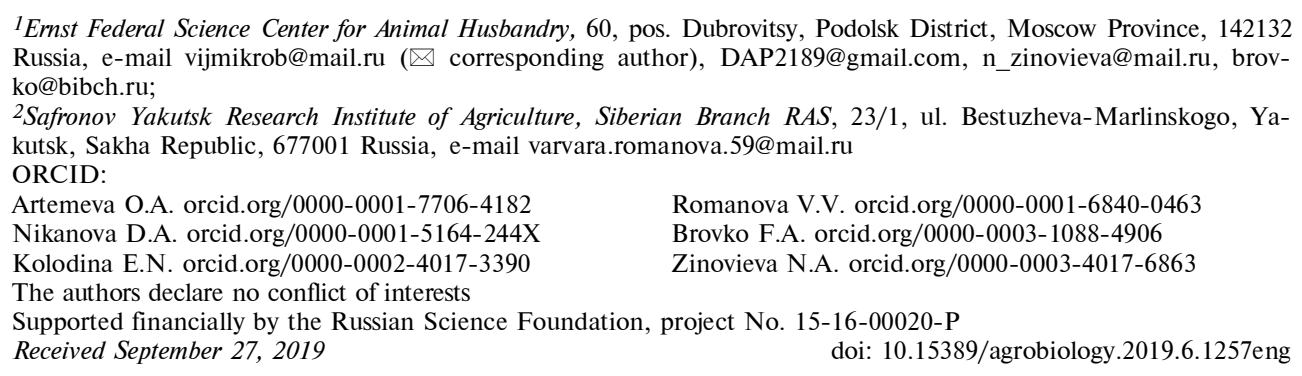

\section{Abstract}

The emergence of multiresistant strains has sharply escalated in recent decades due to the wide use of antimicrobials. The infections caused by Staphylococcus aureus are most common in highly productive dairy animals. The aim of our work was to assess the phenotypic resistance of $S$. aureus strains isolated from cow milk to the main antibacterial drugs used to treat various forms of mastitis in the Russian Federation, as well as to determine their minimum inhibitory concentrations (MIC, $\mathrm{MIC}_{50}$ and $\mathrm{MIC}_{90}$ ). From January to December 2018 milk samples were taken from cows of black-motley Holstein breed at the farms of the Central region of the Russian Federation. A total of 314 milk samples were examined and 447 potential staphylococci were isolated. All isolates were evaluated by conventional phenotypic methods. Only 103 isolates met all the identification criteria and were used for further analysis. The disk diffusion method (DDM) was used to test the susceptibility of the isolated strains to the following antibiotics: penicillin (PEN, $10 \mathrm{U})$, oxacillin (OX, 10 
$\mu \mathrm{g})$, gentamicin (GN, $10 \mu \mathrm{g})$, erythromycin (ER, $15 \mu \mathrm{g})$, and lincomycin ( $\mathrm{LN}, 15 \mathrm{mcg}$ ), rifampicin (RF, $5 \mathrm{mcg}$ ), ciprofloxacin (CP, $5 \mathrm{mcg}$ ), vancomycin (VA, $30 \mu \mathrm{g}$ ), fusidine (FZ, $10 \mu \mathrm{g}$ ) (Pharmacotherapy Research Center, Russia; Mueller Hinton Agar, HiMedia Laboratories Pvt. Ltd., India). A method of double $\left(\log _{2}\right)$ serial dilutions of antibiotics (penicillin, erythromycin, gentamicin, and ciprofloxacin) in TSB medium (from 64 to $0.125 \mathrm{mg} / \mathrm{l}$ ) with $5 \times 10^{5} \mathrm{CFU} / \mathrm{ml}$ inoculum was used to determine the minimum inhibitory concentrations (MIC, $\mathrm{MIC}_{50}, \mathrm{MIC}_{90}$ ) and $\mathrm{LD}_{50}$. The incubation was carried out at $37^{\circ} \mathrm{C}$ for 20 hours $(220 \mathrm{rpm})$. The bacterial growth in TSB medium with antibiotics was evaluated by plating on Baird Parker Agar medium (HiMedia Laboratories Pvt. Ltd., India). The interpretation of the results was carried out according to the recommendation of The European Committee on Antimicrobial Susceptibility Testing (EUCAST). The highest degree of resistance was observed to erythromycin $(82.5 \%)$ and fusidine $(75.7 \%)$. Seven of 103 strains tested were susceptible to all studied antibiotics, 96 isolates were resistant to at least one of them. When assessing multiple resistance (MAR), $65(63.1 \%)$ strains were resistant to four or more antibiotics. The predominant phenotypes for the isolates were $\mathrm{ER}+\mathrm{LN}+\mathrm{FZ}$ and $\mathrm{ER}+\mathrm{CP}$ (58.3\% and $47.6 \%$, respectively). A total of 31 strains of the 47 isolates DDM-resistant to penicillin grew at $\geq 64 \mathrm{mg} / \mathrm{l}$ penicillin, while in the concentration range of $\leq 1.0 \mathrm{mg} / \mathrm{l}$, the growth was observed in $33.0 \%$ of the strains. Fifteen of the 85 erythromycin-resistant isolates showed growth at MIC $\geq 64 \mathrm{mg} / \mathrm{l}$; only 7 strains out of 18 DDMsusceptible ones were in the MIC $\leq 0.5 \mathrm{mg} / \mathrm{l}$ range. A total of $29(28.2 \%)$ of the 103 studied strains were DDM-resistant to gentamicin, $72(60.2 \%)$ showed growth at MIC $\geq 0.5 \mathrm{mg} / \mathrm{l}$, and 5 strains at $\mathrm{MIC} \geq 64.0 \mathrm{mg} / \mathrm{l}$. Only 2 of the $49 \mathrm{DDM}$-resistant strains grew at MIC $\geq 64 \mathrm{mg} / \mathrm{l}$. It is important to point out that the $\mathrm{MIC}_{50}$ was not in the susceptible range for any of the studied antibiotics, and the $\mathrm{MIC}_{90}$ showed the susceptible range for penicillins, aminoglycosides, and fluoroquinolones $(>0.5$, $>0.25$, and $>0.25 \mathrm{mg} / \mathrm{l}$, respectively). In our study the high phenotypic resistance indices of $S$. aureus isolates from cow milk emphasizes the importance of routine screening of $S$. aureus isolates for inducible phenotype resistance.

Keywords: mastitis, Staphylococcus aureus, antibiotics, antimicrobial susceptibility, MIC, phenotypic resistance.

\section{REFER E N C ES}

1. Programma SKAT (Strategiya Kontrolya Antimikrobnoi Terapii) pri okazanii statsionarnoi meditsinskoi pomoshchi: Rossiiskie klinicheskie rekomendatsii /Pod redaktsiei S.V. Yakovleva, N.I. Briko, S.V. Sidorenko, D.N. Protsenko [SCAT (Antimicrobial Therapy Control Strategy) for inpatient care: Russian clinical guidelines. S.V. Yakovlev, N.I. Briko, S.V. Sidorenko, D.N. Protsenko (eds.)]. Moscow, 2018 (in Russ.).

2. Koba I.S., Reshetka M.B. Effektivnoe zhivotnovodstvo, 2013, 3(89): 22-23 (in Russ.).

3. Gamayunov V.M., Amirov A.Kh. Materialy Mezhdunarodnoi nauchno-prakticheskoi konferentsii, posvyashchennoi 85-letiyu so dnya rozhdeniya G.A. Cheremisova i 50-letiyu sozdaniya Voronezhskoi shkoly veterinarnykh akusherov «Sovremennye problemy veterinarnogo akusherstva $i$ biotekhnologii vosproizvedeniya zhivotnykh» [Proc. Int. Conf. dedicated to the 85th birthday of G.A. Cheremisov and the 50th anniversary of the Voronezh school of veterinary obstetricians «Modern problems of veterinary obstetrics and animal reproduction biotechnology»]. Voronezh, 2012: 143-146 (in Russ.).

4. Klimov N.T. Eksperimental'naya i klinicheskaya farmakologiya lekarstvennykh preparatov na osnove dioksidina i doksitsiklina i ikh effektivnost' pri mastite u korov. Avtoreferat doktorskoi dissertatsii [Experimental and clinical pharmacology of drugs based on dioxidine and doxycycline and their effectiveness in mastitis in cows. DSc Thesis]. Voronezh, 2009 (in Russ.).

5. Bulgakova V.G., Vinogradova K.A., Orlova T.I., Kozhevin P.A., Polin A.N. Antibiotiki i khimioterapiya, 2014, 59(1-2): 36-43 (in Russ.).

6. Tsai S.H., Lai H.C., Hu S.T. Subinhibitory doses of aminoglycoside antibiotics induce changes in the phenotype of Mycobacterium abscessus. Antimicrobial Agents and Chemotherapy, 2015, 59(10): 6161-6169 (doi: 10.1128/AAC.01132-15).

7. Wang Q., Sun F.-J., Liu Y. Xiong L.-R., Xie L.-L., Xia P.-Y. Enhancement of biofilm formation by sub inhibitory concentrations of macrolides in icaADBC-positive and -negative clinical isolates of Staphylococcus epidermidis. Antimicrobial Agents and Chemotherapy, 2010, 54(6): 2707-2711 (doi: 10.1128/AAC.01565-09).

8. Kaplan J.B. Antibiotic-induced biofilm formation. The International Journal of Artificial Organs, 2011, 34(9): 737-751 (doi: 10.5301/ijao.5000027).

9. Sanchez C.J. Jr., Shiels S.M., Tennent D.J., Hardy S.K., Murray C.K., Wenke J.C. Rifamycin derivatives are effective against staphylococcal biofilms in vitro and elutable from PMMA. Clinical Orthopaedics and Related Research, 2015, 473(9): 2874-2884 (doi: 10.1007/s11999-015-4300-3).

10. Subrt N., Mesak L.R., Davies J. Modulation of virulence gene expression by cell wall active antibiotics in Staphylococcus aureus. Journal of Antimicrobial Chemotherapy, 2011, 66(5): 979-984 (doi: 10.1093/jac/dkr043).

11. Viana D., Comos M., McAdam P.R., Ward M.J., Selva L., Guinane C.M., GonzálezMuñoz C.M., Tristan A., Foster S.J., Fitzgerald J.R., Penadés J.R. A single natural nucleotide 
mutation alters bacterial pathogen host tropism. Nature Genetics, 2015, 47(4): 361-367 (doi: 10.1038/ng.3219).

12. Rodriges Kh. Meditsinskii sovet, 2017, 1: 34-44 (doi: 10.21518/2079-701X-2017-1-34-44) (in Russ.).

13. Koymans K.J., Vrieling M., Gorham R.D. Jr., van Strijp A.G.J. Staphylococcal immune evasion proteins: structure, function, and host adaptation. In: Staphylococcus aureus. Current Topics in Microbiology and Immunology, vol. 409. F. Bagnoli, R. Rappuoli, G. Grandi (eds.). Springer, Cham, 2015: 441-489 (doi: 10.1007/82_2015_5017).

14. Koop G., Vrieling M., Storisteanu D.M.L., Lok L.S.C., Monie T., van Wigcheren G., Raisen C., Ba X., Gleadall N., Hadjirin N., Timmerman A.J., Wagenaar J.A., Klunder H.M., Fitzgerald J.R., Zadoks R., Paterson G.K., Torres C., Waller A.S., Loeffler A., Loncaric I., Hoet A.E., Bergström K., de Martino L., Pomba C., de Lencastre H., Slama K.B., Gharsa H., Richardson E.J., Chilvers E.R., Haas C., Kessel K., Strijp J.A., Harrison E.M., Holmes M.A. Identification of LukPQ, a novel, equid-adapted leukocidin of Staphylococcus aureus. Scientific Reports, 2017, 7: 40660 (doi: 10.1038/srep40660).

15. Löffler B., Hussain M., Grundmeier M., Brück M., Holzinger D., Varga G., Roth J., Kahl B.C., Proctor R.A., Peters G. Staphylococcus aureus panton-valentine leukocidin is a very potent cytotoxic factor for human neutrophils. PLoS Pathogens, 2010, 6(1): e1000715 (doi: 10.1371/journal.ppat.1000715).

16. Vrieling M., Boerhout E. M., van Wigcheren G.F., Koymans K.J., Mols-Vorstermans T.J., de Haas C.J.C., Aerts P.C., Daemen I.J.J.M., van Kessel K.P.M., Koets A.P., Rutten V.P.M.G., Nuijten P.J.M., van Strijp J.A.G., Benedictus L. LukMF' is the major secreted leukocidin of bovine Staphylococcus aureus and is produced in vivo during bovine mastitis. Scientific Reports, 2016, 6(1): 37759 (doi: 10.1038/srep37759).

17. de Jong N.W.M., Vrieling M., Garcia B.L., Koop G., Brettmann M., Aerts P.C., Ruyken M., van Strijp J.A.G., Holmes M., Harrison E.M., Geisbrecht B.V., Rooijakkers S.H.M. Identification of a staphylococcal complement inhibitor with broad host specificity in equid Staphylococcus aureus strains. Journal of Biological Chemistry, 2018, 293(12): 4468-4477 (doi: 10.1074/jbc. RA117.000599).

18. Kozlova Yu.N., Fomenko N.V., Morozova V.V., Saranina I.V., Tikunov A.Yu., Ganichev D.A., Samokhin A.G., Pavlov V.V., Rozhnova O.M., Bondar' I.A., Zenkova E.V., Nimaev V.V., Klimontov V.V., Tikunova N.V. Vavilovskii zhurnal genetiki i selektsii, 2017, 21(8): 952-958 (doi: 10.18699/VJ17.318) (in Russ.).

19. Safarpoor Dehkordi F., Gandomi H., Akhondzadeh Basti A., Misaghi A., Rahimi E. Phenotypic and genotypic characterization of antibiotic resistance of methicillin-resistant Staphylococcus aureus isolated from hospital food. Antimicrob. Resist. Infect. Control., 2017, 6(1): 104 (doi: 10.1186/s13756-017-0257-1).

20. Safarpoor Dehkordi F., Basti A.A., Gandomi H., Misaghi A., Rahimi E. Pathogenic Staphylococcus aureus in hospital food samples; prevalence and antimicrobial resistance properties. Journal of Food Safety, 2018, 38(6): e12501 (doi: 10.1111/jfs.12501) (Retracted).

21. Momtaz H., Safarpoor Dehkordi F., Rahimi E., Asgarifar A., Momeni M. Virulence genes and antimicrobial resistance profiles of Staphylococcus aureus isolated from chicken meat in Isfahan province, Iran. Journal of Applied Poultry Research, 2013, 22(4): 913-921 (doi: 10.3382/japr.201200673).

22. Hasanpour Dehkordi A., Khaji L., Sakhaei Shahreza M.N., Mashak Z., Safarpoor Dehkordi F., Safaee Y., Hosseinzadeh A., Alavi I., Ghasemi E., Rabiei-Faradonbeh M. One-year prevalence of antimicrobial susceptibility pattern of methicillin-resistant Staphylococcus aureus recovered from raw meat. Tropical Biomedicine, 2017, 34(2): 396-404.

23. Albano M., Karau M.J., Greenwood-Quaintance K.E., Osmon D.R., Oravec C.P., Berry D.J., Abdel M.P., Patel R. In vitro activity of rifampin, rifabutin, rifapentine, and rifaximin against planktonic and biofilm states of staphylococci isolated from periprosthetic joint infection. Antimicrobial Agents and Chemotherapy, 2019, 63(11): e00959-19 (doi: 10.1128/AAC.00959-19).

24. Chambers H.F. The changing epidemiology of Staphylococcus aureus? Emerg. Infect. Dis., 2001, 7(2): 178-182 (doi: 10.3201/eid0702.010204).

25. Lowy F.D. Antimicrobial resistance: the example of Staphylococcus aureus. The Journal of Clinical Investigation, 2003, 111(9): 1265-1273 (doi: 10.1172/JCI18535).

26. Torimiro N., Moshood A.A., Eyiolawi S.A. Analysis of beta-lactamase production and antibiotics resistance in Staphylococcus aureus strains. Journal of Infectious Diseases and Immunity, 2013, 5(3): 24-28 (doi: 10.5897/JIDI2013.0118).

27. Chandrakanth R.K., Raju S., Patil S.A. Aminoglycoside-resistance mechanisms in multidrugresistant Staphylococcus aureus clinical isolates. Current Microbiology, 2008, 56(6): 558-562 (doi: 10.1007/s00284-008-9123-y).

28. Ubukata K., Yamashita N., Gotoh A., Konno M. Purification and characterization of aminoglycoside-modifying enzymes from Staphylococcus aureus and Staphylococcus epidermidis. Antimicrobial Agents and Chemotherapy, 1984, 25(6): 754-759 (doi: 10.1128/AAC.25.6.754).

29. Hosseini S.A.A.M., Khoramrooz S.S., Marashifard M., Parhizgari N., Mansouri F. Frequency of the genes encoding aminoglycoside modifying enzymes in Staphylococcus aureus isolated from hospitalized burn patients. Journal of Mazandaran University of Medical Sciences, 2016, 25(134): 147-157.

30. Rouch D.A., Byrne M.E., Kong Y.C., Skurray R.A. The aacA-aphD gentamycin and kanamy- 
cin resistance determinant of Tn4001 from Staphylococcus aureus: expression and nucleotide sequence analysis. Journal of General Microbiology, 1987, 133(11): 3039-3052 (doi: 10.1099/00221287-133-11-3039).

31. Hancock R.E.W. Aminoglycoside uptake and mode of action - with special reference to streptomycin and gentamicin. I. Antagonists and mutants. Journal of Antimicrobial Chemotherapy, 1981, 8(4): 249-276 (doi: 10.1093/jac/8.4.249).

32. Turutoglu H., Hasoksuz M., Ozturk D., Yildirim M., Sagnak S. Methicillin and aminoglycoside resistance in Staphylococcus aureus isolates from bovine mastitis and sequence analysis of their mecA genes. Veterinary Research Communications, 2009, 33(8): 945-956 (doi: 10.1007/s11259009-9313-5).

33. Wang Z., Han R., Liu Y., Du Q., Liu J., Ma C., Li H., He Q., Yan Y. Direct detection of erythromycin-resistant Bordetella pertussis in clinical specimens by PCR. Journal of Clinical Microbiology, 2015, 53(11): 3418-3422 (doi: 10.1128/JCM.01499-15).

34. Li Y., Liu X., Zhang B., He Q., Wang Z. Where macrolide resistance is prevalent. APMIS, 2015, 123(4): 361-363 (doi: 10.1111/apm.12357).

35. Performance Standards for Antimicrobial Susceptibility Tests; Approved Standard - Twelfth Edition. CLSI Supplement M02-A12. Clinical and Laboratory Standards Institute, USA, 2015.

36. Opredelenie chuvstvitel'nosti mikroorganizmov $k$ antibakterial'nym preparatam. MUK 4.2.1890-04 [Determination of the sensitivity of microorganisms to antibacterial drugs. MUK 4.2.1890-04]. Moscow, 2004 (in Russ.).

37. Shurduba N.A., Sotnikova V.M., Osipova I.S. RZh «Problemy veterinarnoi sanitarii, gigieny $i$ ekologii», 2013, 2(10): 56-57 (in Russ.).

38. Nikulin D.M. Nivy Zaural'ya, 2015, 6: 74-77 (in Russ.).

39. Klibi A., Maaroufi A., Torres C., Jouini A. Detection and characterization of methicillinresistant and susceptible coagulase-negative staphylococci in milk from cows with clinical mastitis in Tunisia. International Journal of Antimicrobial Agents, 2018, 52(6): 930-935 (doi: 10.1016/j.ijantimicag.2018.07.026).

40. Haran P., Godden S.M., Boxrud D., Jawahir S., Bender J.B., Sreevatsan S. Prevalence and characterization of Staphylococcus aureus, including methicillin-resistant Staphylococcus aureus, isolated from bulk tank milk from Minnesota dairy farms. Journal of Clinical Microbiology, 2012, 50(3): 688-695 (doi: 10.1128/JCM.05214-11).

41. Hamiroune M., Berber A., Boubekeur S. Contribution à l'étude de la contamination du lait bovin par les staphylocoques dans certaines fermes de la région d'Alger et son impact sur la santé humaine. Revue scientifique et technique (International Office of Epizootics), 2014, 33(3): 1027-1034.

42. Peles F., Wagner M., Varga L., Hein I., Rieck P., Gutser K., Keresztúri P., Kardos G., Turcsányi I., Béri B., Szabó A. Characterization of Staphylococcus aureus strains isolated from bovine milk in Hungary. International Journal of Food Microbiology, 2007, 118(2): 186-193 (doi: 10.1016/j.ijfoodmicro.2007.07.010).

43. Srednik M.E., Usongo V., Lépine S., Janvier X., Archambault M., Gentilini E.R. Characterisation of Staphylococcus aureus strains isolated from mastitis bovine milk in Argentina. Journal of Dairy Research, 2018, 85(1): 57-63 (doi: 10.1017/s0022029917000851).

44. Bidya S., Suman R.S. Comparative study of three $\beta$ lactamase test methods in Staphylococcus aureus isolated from two Nepalese hospitals. Open Journal of Clinical Diagnostics, 2014, 4: 47-52 (doi: 10.4236/ojcd.2014.41009).

45. Shi D., Hao Y., Zhang A., Wulan B., Fan X. Antimicrobial resistance of Staphylococcus aureus isolated from bovine mastitis in China. Transboundary and Emerging Diseases, 2010, 57(4): 221224 (doi: 10.1111/j.1865-1682.2010.01139.x).

46. Aarestrup F.M., Jensen N.E. Development of penicillin resistance among Staphylococcus aureus isolated from bovine mastitis in Denmark and other countries. Microbial Drug Resistance, 1998, 4(3): 247-256 (doi: 10.1089/mdr.1998.4.247).

47. Nunes S.F., Bexiga R., Cavaco L.M., Vilela C.L. Technical note: antimicrobial susceptibility of Portuguese isolates of Staphylococcus aureus and Staphylococcus epidermidis in subclinical bovine mastitis. Journal of Dairy Science, 2007, 90(7): 3242-3246 (doi: 10.3168/jds.2006-739).

48. Kaase M., Lenga S., Friedrich S., Szabados F., Sakinç T., Kleine B., Gatermann S.G. Comparison of phenotypic methods for penicillinase detection in Staphylococcus aureus. Clinical Microbiology and Infection, 2008, 14(6): 614-616 (doi: 10.1111/j.1469-0691.2008.01997.x).

49. The European Committee on Antimicrobial Susceptibility Testing. Routine and extended internal quality control as recommended by EUCAST. Version 8.0, 2018. Rezhim dostupa http://www.eucast.org/ast_of_bacteria/previous_versions_of_documents/. Available 18.12.2019.

50. Farahani A., Mohajeri P., Gholamine B., Rezaei M., Abbasi H. Comparison of different phenotypic and genotypic methods for the detection of methicillin-resistant Staphylococcus aureus. North American Journal of Medical Sciences, 2013, 5(11): 637-640 (doi: 10.4103/1947-2714.122305).

51. Pitkälä A., Haveri M., Pyörälä S., Myllys V., Honkanen-Buzalski T. Bovine mastitis in Finland 2001 - prevalence, distribution of bacteria, and antimicrobial resistance. Journal of Dairy Science, 2004, 87(8): 2433-2441 (doi: 10.3168/jds.S0022-0302(04)73366-4). 